\title{
GENERIC BARE PLURALS IN RUSSIAN AND BEYOND
}

\author{
Daria Seres*
}

\begin{abstract}
This paper focuses on indirect reference to kinds achieved by means of bare plural nominal expressions in Russian, which is a language without articles. These NPs refer to sums of individuals, whose denotation is built on Number. Their default interpretation is indefinite, while generic and definite readings are a result of a pragmatic strengthening, i.e. these readings appear only in certain environments (argument position of k-level predicates, subject position of characterising statements) and depend on the world knowledge of interlocutors. Generically and definitely interpreted expressions are similar to each other, being characterised by maximality, identifiability and presupposition of existence. However, the former ones cannot be spatiotemporally localised or anaphorically anchored. Going beyond Russian, it is suggested that in some languages genericity (along with definiteness) may be encoded semantically by means of a definite article, while in others it is pragmatically inferred on bare NPs; this difference can account for the inter- and intralinguistic variation in the expression of genericity.
\end{abstract}

Keywords: genericity, articleless languages, bare plurals, Russian

\section{Introduction}

Genericity conceived as reference to kinds can be considered a universal phenomenon of human language and cognition as it is found in all natural languages. Even though genericity has been extensively studied in linguistics since the 1970s (Lawler 1973, Dahl 1975, Carlson 1977a, 1977b, Krifka \& Gerstner 1987, Krifka et al. 1995, Dayal 2004, Mari et al. 2012 and many others), it is still a rather highly disputed topic. This article ${ }^{1}$ discusses several aspects of the expression of genericity in Russian as a language without articles and aims at contributing to a better understanding of this phenomenon.

It is also important to notice that genericity has mostly been investigated on the empirical data from Germanic and Romance languages ${ }^{2}$, i.e. languages with articles. Genericity in languages without articles is still rather understudied and does not have a long tradition to look back on, which is what motivated my theoretical investigation, presented in this paper. ${ }^{3}$ Research on genericity in articleless languages has been done by Dayal $(2004,2011)$ drawing on the empirical data from Hindi and Russian, Topolinjska (2006) on Polish (in comparison with Macedonian), and Filip (1993), Filip \& Carlson (1999) on Czech. In modern Russian linguistics, genericity has received very little attention, with a notable exception of Borik \& Espinal's (2019 a, b) proposal for Russian definite kinds, which I take as a starting point for my research.

\footnotetext{
* Universitat Autònoma de Barcelona, daria.seres@uab.cat.

${ }^{1}$ I acknowledge financial support from the Spanish MINECO (FFI2017-82547-P) and the Generalitat de Catalunya (2017SGR634).

${ }^{2}$ Some works on the expression of genericity in Romance languages include the following: Longobardi (2001) for Italian, Beyssade (2005) for French, Borik \& Espinal (2015) for Spanish, and Müller (2002), Dobrovie-Sorin \& Pires de Oliveira (2008), Cyrino \& Espinal (2015) for Brazilian Portuguese.

${ }^{3}$ A more detailed proposal for the analysis of genericity in Russian is presented in Seres (2020).
}

Bucharest Working Papers in Linguistics XXII, 1, 33-54, e-ISSN 2392-8093, ISSN-L 2069-9239

DOI: 10.31178/BWPL.22.2.2 
One of the challenges that languages without articles, such as Russian, represent for linguists is the ability of bare nominals in these languages to appear freely in argument positions and to have various interpretations: indefinite, definite and generic, as represented in (1). Thus, an important task is to distinguish between these interpretations, to define the default one and to explain the rise of the other ones.

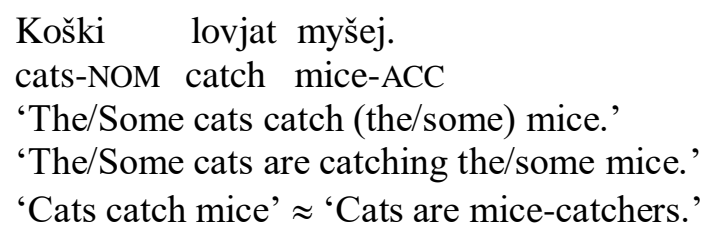

In this paper, I focus on bare plural nominals in Russian that are found in subject position. ${ }^{4}$ I propose that their default interpretation is indefinite - which is in line with Heim's (2011) hypothesis for bare nominals in languages without articles - and that other interpretations (definite and generic) are pragmatically inferred, i.e. they can be construed as a result of strengthening of an indefinite. Furthermore, I posit that a generic interpretation of bare nominals is similar to a definite one by three criteria: maximality (understood as the totality of reference or an inclusive reference), identifiability (conceived as a type of familiarity), and presupposition of existence. The difference between the two interpretations consists in the inability of bare nominals to be interpreted generically when they are spatiotemporally or anaphorically anchored. In these cases, the most salient interpretation is the definite one.

After this introduction, in section 2 I briefly talk about kinds as a linguistic phenomenon and in the two following sections I focus on the expression of the indirect reference to kinds in Russian. Section 3 is devoted to the semantic composition of bare plural expressions in Russian, while in section 4 I look at the environments where bare plural NPs may be interpreted generically. In section 5, I show the similarities between genericity and definiteness, and further, in the discussion in section 6, I propose that some languages encode these two readings semantically, while in some others they are pragmatically inferred. This may explain the intra- and inter-linguistic variation in the expression of genericity on plural nominals.

\section{Reference to kinds in natural language}

Before speaking about genericity as the expression of the human ability to think and talk not only about objects of the real world, but also about kinds, which represent abstract classes of objects, it is important to clarify the notion of "kind", or "genus". 5

\footnotetext{
${ }^{4}$ For the interpretation of plural nominals in object position the reader is referred to Seres \& Espinal (2018, 2019).

${ }^{5}$ It should be noted that kinds are abstract constructs postulated in linguistics, philosophy, cognitive science, etc. to account for the phenomenon of genericity, that is why they can be construed differently depending on a framework or a semantic ontology adopted in each piece of research. Chierchia (1998: 35) in his influential
} 
Kinds may be conceived as abstract sortal concepts that form a "mental catalogue", which is developed in human beings during their cognitive genesis, when they are confronted with the real world of objects (Mueller-Reichau 2011:35). Kinds serve to categorise and individuate these objects.

Therefore, kinds may be viewed as a result of generalising over instances (instantiations), which are infinitely many, as claimed in Prasada (2016). It is important to notice, however, that "the product of this generalisation abstracts away from instantiations and semantically behaves like an entity without any internal structure" (Borik \& Espinal 2015: 183). The main difference between kinds and their instantiations is that, being abstract, the former do not exist in space or time, but only in the mind of the speaker (Mueller-Reichau 2011: 153). The existence in space and time ${ }^{6}$, i.e. spatiotemporal localisation, is what distinguishes instantiations of kinds from kinds.

It is important to point out that by means of language speakers may refer to either particular objects (individuals) of the real world (i.e. instantiations of kinds), or to abstracts concepts (i.e. kinds) by virtue of which they sort these objects (Mueller-Reichau 2011: 101). For English, the idea that a definite singular NP with a generic reading, like the one in (2a), denotes a kind or a species itself, while a bare plural expression, like the one in (2b), refers to a sum of its instantiations, can be traced back to Jespersen (1927). The subject NP in (2a) may, thus, be conceived as having direct reference to kinds, while the one in (2b) refers to a kind indirectly, i.e. by means of a reference to a sum of individual representatives that belong to this kind. ${ }^{7}$

(2) a. The rhino is on the verge of extinction.

b. Rhinos are on the verge of extinction.

This idea is further developed in Borik \& Espinal's (2015, 2019a,b) works on definite kinds in Spanish and Russian. They conceive NPs like the one in (2a) as atomic integral intensional entities of type $e^{k}$, which do not license access to instances of a kind. In languages with articles, such as English and Romance, they are composed by applying an iota operator (the meaning of uniqueness encoded by the definite article) to the meaning of nouns (properties of kinds, of type $\left\langle\mathrm{e}^{\mathrm{k}}, \mathrm{t}\right\rangle$ ). ${ }^{8}$ As far as Russian is concerned, Borik \& Espinal (2019b) propose to derive the same meaning by applying of a choice function to properties of kinds, which would yield the only entity that has the property of

paper on the expression of genericity in different languages claims that "kinds are whatever your favourite worldview says they are".

${ }^{6}$ Notice that the existence in space and time also includes hypothetical, imaginary and counterfactual worlds.

${ }^{7}$ On the difference between direct and indirect reference to kinds also see Mari et al. (2012: 26).

${ }^{8}$ Following Espinal \& McNally (2007), Dobrovie-Sorin \& Pires de Oliveira (2008), Espinal (2010), Borik \& Espinal (2015) and other scholars, I assume that the denotation of a common noun is a property of a kind that can be formally represented as follows:

(i) $\quad[[\mathrm{N}]]=\lambda \mathrm{x}^{\mathrm{k}}\left[\mathrm{P}\left(\mathrm{x}^{\mathrm{k}}\right)\right]$,

where $\mathrm{P}$ stands for a property corresponding to the descriptive content of $\mathrm{N}$, and $\mathrm{x}^{\mathrm{k}}$ is a kind entity, such that the property $\mathrm{P}$ applies to $\mathrm{x}^{\mathrm{k}}$. Notice also that the idea common nouns denote properties can be traced back to Frege (1892); I am grateful to an anonymous reviewer for pointing this out. 
a given kind. Thus, even though the sematic derivation is different, its result is the same for languages with and without articles.

In this work, I adopt Borik \& Espinal's (2019a, 2019b) analysis of direct reference to kinds in Russian and build on it my analysis of indirect reference to kinds. I claim that bare plural nominals refer to sums of individuals. Their semantic derivation is based on Number, unlike the one of definite kinds, which have a default morphophonological singular form but no semantic or syntactic Number.

As argued further in this paper, a sum of individuals denoted by a bare plural NP in Russian may be interpreted as maximal and may be intensionalised in certain contexts, thus, making kind-reference possible, even though it is indirect.

\section{The semantics of generic bare plurals in Russian}

As was mentioned before, kinds may be accessed by speakers directly or indirectly. In the rest of the article, I focus on the indirect reference to kinds, i.e. reference to individuals, whose sum represents the totality of instances of a kind. In Russian this reading is available for bare plural nominals, I call this reading "generic". I show that reference to the totality of instances (i.e. a maximal sum of instances) is crucially different from direct reference to kinds as the former involves semantic and syntactic Number.

\subsection{The presence of Number}

Unlike definite kinds, briefly discussed in Section 2, that do not allow access to instantiations of the kind, generic plurals may license access to individual entities, which means that Number is present in their structure. The presence of syntactic and semantic Number can be empirically proven for Russian bare plurals with a generic reading.

For instance, they can establish a discourse semantic relationship with the indefinite partitive pronoun nekotorye 'some' as its potential antecedent (3a), while definite kinds do not allow such licensing ( $3 b)$.

a. Nosorogi naxodjatsja na grani isčeznovenija. Nekotorye rhinos-NOM.PL are.found on verge extinction-GEN some special'no oxranjajutsja $\mathrm{v}$ zooparkax. on.purpose are.guarded in zoos.

'Rhinos are on the verge of extinction. Some (of them) are specially guarded in zoos.'

b. Nosorog naxoditsja na grani isčeznovenija. *Nekotorye rhino-NOM.SG is.found on verge extinction-GEN some special'no oxranjajutsja $\mathrm{v}$ zooparkax. on.purpose are.guarded in zoos. Intended: 'The rhino is on the verge of extinction. Some (of them) are specially guarded in zoos.' 
The same holds true for reciprocal constructions, which can occur only with semantically plural antecedents (4a), but not with definite kinds (4b), which are devoid of Number.
a.
Nosorogi agressivny
po otnošeniju drug $\mathbf{k}$ drugi rhinos-NOM.PL aggressive-NOM.PL in relation one to another 'Rhinos are aggressive towards one another.'
b. *Nosorog agressiven po otnošeniju drug $\mathbf{k}$ drugu rhino-NOM.SG aggressive-NOM.SG in relation one to another Intended: 'The rhino is aggressive towards one another.'

Moreover, generic plural expressions can serve as antecedents to plural personal pronouns, interpreted existentially, as illustrated in (5a), which is impossible for definite kinds (5b).

a. Tykvy xranitsja dolgo poètomy Nikita kupil ix pumpkins store.themselves long that.is.why Nikita bought them mnogo.

many

'Pumpkins can be stored for a long time that's why Nikita bought many of them.'

(Bronnikov 2007: 7, ex.14)

b. *Tykva xranitsja dolgo, poètomu Nikita kupil ix mnogo. pumpkin stores.itself long that.is.why Nikita bought them many Intended: 'The pumpkin can be stored for a long time that's why Nikita bought many of them.'

As shown in examples (3a), (4a) and (5a), Russian generic bare plurals, indeed, allow access to individual entities, having morphosyntactic Number which is interpreted semantically, whereas definite kinds do not. ${ }^{9}$ So, there is empirical motivation for postulating Number in the semantic composition of bare plurals in Russian. ${ }^{10}$ Number may be conceived as a realisation or instantiation operator (R) (see Carlson 1977a, Déprez 2005) turning properties of kinds of type $<\mathrm{e}^{\mathrm{k}}, \mathrm{t}>$ into properties of individuals of type $\left\langle e^{\mathrm{o}}, \mathrm{t}>\right.$ (Espinal \& McNally 2007, Espinal 2010, Borik \& Espinal 2015). An overt

\footnotetext{
${ }^{9}$ Notice that English generic bare plurals also show the ability to serve as antecedents for pronouns understood non-generically and viceversa, while it is not possible for definite kinds:

(i) a. Lemmings are protected by law, but Mick goes ahead and traps them anyways.

b. Mick traps lemmings, even though he knows they are protected by law.

(ii) a. The lemming is protected by law, *but Mick goes ahead and traps them anyways. b. Mick traps the lemming, *even though he knows they are protected by law.

${ }^{10} \mathrm{I}$ am not making any claims about other languages that have bare plurals, but this kind of analysis might be extended to them.
} 
Number determines the realisation of bare nominal expressions as singular individuals (reference to atoms) or as plural individuals (reference to sums). ${ }^{11}$

\subsection{Possible type-shifters}

At this stage of semantic composition, after Number has been applied to the denotation of a common noun, we have properties of individuals (type $\left\langle\mathrm{e}^{\mathrm{o}}, \mathrm{t}\right\rangle$ ). In order for them to function as arguments they have to be shifted to type $e$ (individual objects) or to $\langle\langle\mathrm{e}, \mathrm{t}\rangle, \mathrm{t}\rangle$ (generalised quantifiers) (Partee 1987, Chierchia 1984, 1998, and many others). It is important to point out that in languages without articles all type-shifting operations are covert. The main challenge is, thus, to find logical or empirical motivation for postulating a certain operator in Russian (or other articleless languages).

There have been several proposals for covert type-shifting operations in Russian. Chierchia (1998), in his seminal work on reference to kinds across languages, claims that generic plurals in Russian pattern with the English ones and gives a similar account for them, deriving the generic interpretation by means of the nom $/ \cap$ operator. ${ }^{12}$ The only test that Chierchia (1998) proposes for the presence of the "down" operator is the ability of bare plurals to serve as arguments for kind-level predicates. An analysis involving this operator would predict the derivation of the existential reading of bare plurals in Russian (through Derived Kind Predication Rule that turns a kind-denoting argument into an existentially bound indefinite) ${ }^{13}$, but would not explain the possiblity of having a definite interpretation, associated with an iota operator. Moreover, as the nom $/ \cap$ is not lexicalised, the option of having an intensionalised iota ${ }^{14}$ (as proposed for Romance languages) in its place cannot be excluded. So, I will not assume that there is nom $/ \cap$ in Russian because of the absence of any independent empirical evidence for its existence, apart from the mere existence of bare plurals themselves. ${ }^{15}$

Dayal (2004, 2011, 2017), revising Chierchia's approach, proposes a theory for Hindi and Russian (both are languages without articles), in which she claims that bare nominals are ambiguous between generic and definite. The difference between Chierchia's and Dayal's approaches to the meaning of bare nominals cross-linguistically is presented in (6):

\footnotetext{
${ }^{11}$ The meaning of morphosyntactically plural nominals can be represented in the following way (Borik and Espinal 2015: 188, ex. 23b):$$
\text { (i) } \quad\left[\mathrm{Num}^{+\mathrm{PL}}\right]=\lambda \mathrm{P} \lambda \mathrm{x}^{\mathrm{o}} \lambda \mathrm{x}^{\mathrm{k}}\left[\mathrm{P}\left(\mathrm{x}^{\mathrm{k}}\right) \& \mathrm{R}\left(\mathrm{x}^{\mathrm{o}}, \mathrm{x}^{\mathrm{k}}\right) \& \mathrm{x}^{\mathrm{o}} \in \mathrm{Sum}\right]
$$$$
{ }^{12} \text { Chierchia (1998b: 351) defines the nom/“down" operator as represented in (i): }
$$$$
\text { (i) For any property } \mathrm{P} \text { and world/situation } \mathrm{s} \text {, }
$$$$
{ }^{\cap} \mathrm{P}=\lambda \mathrm{s} \mathrm{P}_{\mathrm{s}} \text {, if } \lambda \mathrm{s} \mathrm{P}_{\mathrm{s}} \text { is in } \mathrm{K} \text {, undefined otherwise, }
$$$$
\text { where } \mathrm{P}_{\mathrm{s}} \text { is the extension of } \mathrm{P} \text { in } \mathrm{s} \text {, and } \mathrm{K} \text { is the ontological domain of kinds. }
$$$$
{ }^{13} \text { Chierchia (1998: 364) represents Derived Kind Predication rule in the following way: }
$$$$
\text { (i) If } \mathrm{P} \text { applies to objects and } \mathrm{k} \text { denotes a kind, then } \mathrm{P}(\mathrm{k})=\exists \mathrm{x}[\mathrm{k}(\mathrm{x}) \& \mathrm{P}(\mathrm{x})]
$$$$
{ }^{14} \text { In Montague's (1970) intensional logic the down operator is defined as follows, i.e. being equivalent to an }
$$$$
\text { intensionalised iota: }
$$$$
\text { (i) } \quad \wedge^{\wedge}=\wedge \mathrm{x} \mathrm{P}(\mathrm{x})
$$

${ }^{15}$ Notice that there is no empirical evidence for this operator in English either, apart from the existence of bare plurals, which are "anomalous" for a language with articles.
} 
(6) a. Chierchia (1998): $\cap>\{1, \exists\} \Rightarrow$ bare NPs can only be kind terms.

b. $\quad$ Dayal (2004): $\{\cap, 1\}>\exists \Rightarrow$ bare NPs can be kind terms and definites, but not indefinites.

The main problem with these approaches that postulate covert type-shifting for languages without articles is that there is no empirical evidence for it. Another problem is that they make incorrect empirical predictions. According to Dayal's theory, a fullfledged indefinite interpretation would be impossible for Russian bare nominals. Nevertheless, based on empirical evidence, it can be claimed that Russian bare nominals may function as bona fide indefinites.

An indefinite nominal is generally characterised by being able to have both wide and narrow scope (Carlson 1977a, Dayal 2004, 2011). According to this test, Russian bare plural nominals may be considered indefinite as they may have both wide and narrow scope, for instance, with respect to modal operators. In (7), both interpretations (want $>\exists$ and $\exists<$ want) are available, even though the narrow scope one is easier to obtain:
Ivan xočet poznakomit'sja s kino-zvëzdami.
Ivan wants meet with movie-stars
'Ivan wants to meet movie-stars.' and
'There exist movie-stars that Ivan wants to meet.'

Moreover, it should be noted that in some cases only a wide-scope interpretation is available, as illustrated in (8a). In order to obtain the narrow-scope interpretation, the bare plural direct object has to be marked for the genitive case, as in (8b).

(8)a. Ivan ne zametil pjatna na polu.

Ivan not noticed spots-ACC on floor

'There were spots on the floor that Ivan didn't notice.'

b. Ivan ne zametil pjaten na polu.

(Bronnikov 2006: 6, ex. 24) ${ }^{16}$

Ivan not noticed spots-GEN on floor

'Ivan didn't notice spots on the floor.'

Based on their scopal properties bare plurals in Russian can be considered true indefinites (see also Seres \& Borik, in press). This hypothesis goes in line with Heim's (2011: 1006) proposal that in languages without articles bare NPs "may simply be indefinites". I suggest that the default interpretation of bare nominals in Russian is indefinite, and that the other interpretations (generic and definite) are pragmatically inferred, so, no covert type-shifting is needed to derive these interpretations. ${ }^{17}$

\footnotetext{
${ }^{16}$ Modeled on Carlson (1977: 11, ex. 18).

${ }^{17}$ As far as the derivation of the indefinite is concerned, two semantic mechanisms have been proposed in the literature to derive indefinites: existential quantification and choice functions (Reinhart 1997). The exact analysis of Russian indefinites is yet to be developed, and it is outside the scope of this article.
} 


\section{The rise of a generic interpretation of Russian bare plural subjects}

As was stated in the previous subsection, a generic reading of bare plural nominals in Russian is inferred pragmatically. In this section, I show that this interpretation arises only in certain environments. That is, the way speakers interpret bare plural nominals in subject position depends on the type of predicate (kind- or individual-level vs. stagelevel), ${ }^{18}$ as well as on the type of sentence (characterising vs. episodic) and contextual factors, such as the presence or absence of anaphoricity and spatiotemporal localisation.

\subsection{Verb-driven genericity ${ }^{19}$}

First of all, it should be noticed that the rise of a generic interpretation on a bare plural nominal is constrained by the type of predicate. This phenomenon, called V-driven genericity, may be understood as a type of coercion where the predicate forces a shift in meaning (from individuals to kind) on the denotation of a nominal phrase in its argument position in order for the argument to satisfy the selectional requirements of the predicate (Borik \& Espinal 2015).

Russian bare plurals always get a generic interpretation when combined with kindlevel (k-level) predicates, as illustrated in (9). In this case, the generic interpretation of the nominal does not come from the nominal itself, as the bare plural nominal does not refer to a kind, but to a sum of individuals, as discussed in the previous section. The shift in meaning consists in intensionalisation (à la Chierchia 1998) of the plural argument, which refers to a sum of individuals, in order for the nominal to denote a kind (in this case, indirectly).

(9) Sobaki široko rasprostraneny.

dogs widely spread

'Dogs are widely spread.'

Preverbal bare plurals in combination with individual-level (i-level) predicates may get various readings in Russian. Out of the blue, when the context is not defined (i.e. the reference domain is not restricted), the subject nominal in (10) is interpreted generically, without blocking other types of interpretation which depend on the context:

$$
\begin{aligned}
& \text { Sobaki lajut. } \\
& \text { dogs bark } \\
& \text { 'Dogs bark.' }
\end{aligned}
$$

\footnotetext{
${ }^{18}$ The classification of predicates into kind-, individual- and stage-level was proposed for English in Carlson (1977a, 1977b). It is not uncontroversial and does not always work for languages, other than English, but it serves well for the purposes of this paper.

${ }^{19}$ The term verb-driven, or V-driven, genericity was proposed in Borik \& Espinal (2015) for Spanish. I suggest that this phenomenon is also found in other languages, including Russian.
} 
The subject nominal in (10) may also get a definite interpretation, i.e. 'The dogs bark.', if the sentence is about a contextually salient group of dogs that is known to the speaker and the listener.

The only case when the generic interpretation of the subject is excluded is in combination with stage-level (s-level) predicates. This is due to the nature of these predicates, whose arguments need to be spatiotemporally localised, which is exactly what generic nominals lack (see section 2 for the difference between kinds and individuals). The sentence in (11) contains a lexical s-level predicate, and the generic interpretation of the subject nominal is not possible - the most salient interpretation in this case is definite (however, an indefinite one is not excluded either).

(11) Sobaki vidnejutsja vdaleke.

dogs are.seen in.the.distance

'The dogs are seen in the distance.'

It is also interesting to look at cases of conjunction of two predicates in one sentence. In the combination of an i-level predicate ('be intelligent') with a k-level predicate ('be widespread') the subject gets interpreted generically (12), while in the combination of the same i-level predicate with an s-level predicate ('be barking') the interpretation of the subject is definite (13). However, a conjunction of a k-level and an s-level predicate is infelicitous (14), as it could have been predicted from their selectional requirements.

(12) Sobaki očen' umnye i oni široko rasprostraneny. dogs very intelligent and they widely spread

'Dogs are intelligent and (they) are widespread.'

(13) Sobaki očen' umnye i oni sejčas lajut na ulice.

dogs very intelligent and they now bark in street

'The dogs are very intelligent and they are now barking outside.'

\#Sobaki široko rasprostraneny i oni sejčas lajut na ulice.
dogs widely spread and they now bark in street
Intended: 'Dogs are widespread and they are now barking outside.'

The combination of the two predicates is felicitous in (12) as both of them admit arguments with a generic reference; the combination in (13) is also felicitous because both predicates admit arguments with an individual reference. However, (14) is unacceptable as the two predicates require different types of arguments (kind-referring vs. individual-referring).

To sum up, I have shown that the interpretation of preverbal bare plural nominals in subject position of intransitive predicates may indeed depend on the type of predicate. A generic interpretation always appears when the predicate is k-level, but is excluded in the case of an s-level predicate. I-level predicates can yield both a generic and a definite interpretation, which may be disambiguated by context. In this case it is important to distinguish between characterising and episodic predications, which I do in the following subsection. 


\subsection{Genericity in characterising sentences}

Characterising sentences are considered to be expressions of sentence-level genericity (Krifka et al. 1995), i.e. genericity comes as a feature of the whole sentence, not of the subject nominal. This is a widespread phenomenon in natural language. Speakers use characterising sentences to talk about regularities that hold of individuals, events, states or situations and to make generalisations about the world. Such statements denote "propositions which do not express specific episodes or isolated facts, but instead report a kind of general property, that is, report a regularity which summarises a group of particular episodes or facts" (Krifka et al. 1995: 2).

Unlike episodic predications, which attribute an accidental property to a particular individual or a group of individuals, or report isolated events, situations or states, characterising sentences express an "essential" property (Krifka et al. 1995). They are also categorical judgements in terms of Kuroda (1972), i.e. their subject is Topic, which means that it is identifiable for the speaker and for the listener. Naturally, if one wants to speak about some essential characteristics of an individual or a kind, they need to have some previous knowledge of it.

It is also important to notice that charactersing sentences are law-like, expressing some general truth, and, thus, temporally unbounded. Thus, in Russian characterising sentences the present imperfective - the most unmarked tense and aspect - is generally used. $^{20}$

It is crucial to notice that in Russian one and the same sentence (e.g. Sobaki lajut 'Dogs bark') may be interpreted as either episodic, like in (15), or characterising of specific individuals, like in (16), or characterising of a kind (through its instances), like in (17). The bare plural nominal subject may be associated with an indefinite reading, a definite or an indefinite one, or a generic reading, respectively.

(15) Context: On the phone.

Ja tebja ne slyšu. Zdes' sobaki lajut.

I you-ACC not hear here dogs bark

'I can't hear you. Some/the dogs are barking here.'

(16) U nas doma živut Bobik i Žučka. Sobaki lajut

at us-GEN home live Bobik and Zhuchka dogs bark

po nočam, i my ne možem spat'.

at nights and we not can sleep

'At home there live Bobik and Zhuchka. The dogs bark at night, and we can't sleep.'

${ }^{20}$ The past tense is also possible but it gives a life-time effect, i.e. an inference that the subject is out of existence. Spatiotemporal anchoring, however, is generally not possible for characterising sentences. For instance, the sentence in (ii) with a perfective predicate (temporal localisation) cannot be interpreted as characterising, and the subject cannot be interpreted as generic.

(i) Dinozavry eli vodorosli. generic/definite/indefinite dinosaurs ate-IPF kelp

'Dinosaurs ate kelp.'

(ii) Dinozavry s'eli vodorosli.

dinosaurs ate-PF kelp

'The/some dinosaurs ate kelp.'

definite/indefinite/\#generic 
- Kakie zvuki proizvodjat domašnie životnye? what sounds produce domestic animals

- Sobaki lajut, koški mjaukajut, popugai razgovarivajut. dogs bark cats meow, parrots talk

'- What sounds do domestic animals make? - Dogs bark, cats meow, parrots talk.'

How do speakers of Russian choose the correct interpretation of the subject nominal? Apparently, they have to rely on the discourse context. The two relevant factors are the presence or absence of spatiotemporal localisation and anaphoricity.

Spatiotemporal localisation (or anchoring) represents spatial locations and times involved or referred to in an utterance. It usually manifests itself through the presence of an adverbial modifier indicating a place or a time. As was stated in section 2, kind entities differ from individual entities by the absence of spatiotemporal localisation. Thus, the generic interpretation (indirect reference to a kind) of bare plurals is disallowed when the utterance is spatiotemporally localised. In (15) the spatiotemporal localisation is realised through the use of the deictic element zdes' 'here' and the situation of a phone call involving immediacy, which is reflected in the use of the progressive aspect in English (see the translation of this sentence) but is not marked morphologically on a Russian verb. In (16) the spatiotemporal localisation is carried out by means of adverbial modifiers doma 'at home' and po nočam 'at night'.

Anaphoricity (or anaphoric anchoring) also acts as a localising factor for a referent in a given situation. It provides an unambiguous definite reading for the bare nominal, based on the presence of the referent in the preceding discourse (direct anaphoricity). For instance, in (16), the proper names of dogs are present in the context, which make the bare nominal sobaki 'dogs' be interpreted as definite. A generic reading is excluded in this case.

Anaphoricity may also be associative (also known as bridging or inferrable definiteness) (Clark 1975, Hawkins 1978, Schwarz 2012, among many others). Consider the interpretation of bare plurals sobaki 'dogs' and kosti 'bones' in example (18).

(18) Context: On Sundays we eat lamb. We don't throw anything away becausethere's an animal shelter nearby.

Sobaki edjat kosti s udovol'stviem.

dogs eat bones with pleasure

'The dogs eat the bones with pleasure.'

In example (18) sobaki 'dogs' is situationally interpreted as 'the dogs from the animal shelter'. The definiteness of kosti 'bones' is inferrable from encyclopedic and common ground information. The antecedent is not the referent of the definite itself, but stands in some salient relationship to it, e.g lamb is not directly anaphoric with bones, but it can be inferred that the speaker means 'the bones that are left from the lamb'.

The generic reading of a bare nominal is excluded in the cases of both direct and associative anaphoricity, as the domain of reference of the nominal is contextually restricted, which is incompatible with the unbounded character of generic nominals. Unboundedness may be understood as refence to all instantiations of a kind, which are 
indefinitely many (Prasada 2016). Declerck (1986: 182) claims that in order for a generic meaning to arise the domain of reference must be unbounded, i.e. the set of elements to which the predication applies cannot be restricted by the context.

I have shown that the main difference between generically and definitely interpreted NPs is the incompatibility of the former with spatiotemporal and anaphoric anchoring. Nevertheless, genericity and definiteness as types of reading have a lot in common. I focus on the similarities between the two interpretations in the section coming below.

\section{Genericity and definiteness}

In section 3, I suggested, contra Dayal (2004), that the default reading of bare nominals in Russian is the indefinite one. Disagreeing with Dayal on the question of the default interpretation of bare nominals in languages without articles, I accept her idea that articleless languages, such as Russian and Mandarin, show a close affinity between a definite reading and a generic one (Dayal 2004, 2017).

I propose that generically interpreted bare plural nominals have a lot in common with definite ones, as they are characterised by maximality (the totality of reference, inclusive reference), identifiability (as a type of familiarity), and presupposition of existence. Furthermore, I hypothesise that, while these definiteness effects are encoded semantically by means of an overt article in definite generic plurals in Romance languages, and also in typologically different languages, such as Hungarian, Greek, Arabic (see Behrens 2005 for details) and Slavic languages with articles (Macedonian and Bulgarian), they are pragmatically inferred in languages with generic bare plurals, such as Russian (and possibly English). ${ }^{21}$

In the following subsections, I review the above-mentioned characteristics of generic plurals that they share with definitely interpreted nominals. These definiteness effects are expected to be found cross-linguistically, so, I am mostly using English examples for simplicity.

\subsection{Maximality}

Maximality, which can be understood as inclusiveness or the totality of reference (Hawkins 1978), is one of the characteristics that generic and definite plurals share. A discourse referent is considered to be maximal if it ranges over all entities that satisfy its descriptive content, within a contextual restriction for definites and with no contextual restriction for generics (Seres 2020). The understanding of definiteness as maximality in

\footnotetext{
${ }^{21}$ It is important to notice that Heim (2011: 1008-1009) claims that generics in English are "unrestricted definites", even though they have no definite article. They can be understood as maximal pluralities, which in her view are equivalent to kinds. In such cases the overt definite/indefinite distinction is neutralised and the surface realisations are dissociated from an abstract determiner with a $[ \pm \mathrm{DEF}]$ feature, and the $[+\mathrm{DEF}]$ feature is just spelled out as zero.
} 
plural nominals in languages with articles can be traced back to Vendler (1967), who claimed that definite NPs imply "completeness". According to Sharvy (1980), the definite article applied to plural expressions indicates "totality". However, in languages without articles the perceived maximality has to have a different source, not the definite article.

I propose that maximality in generic bare nominals can be seen as a pragmatic effect. The generic reference can be understood as an inclusive one (Declerck 1987, Laca 1990, among others) in the sense that it involves reference to all the instantiations of a kind, both atoms and sums, both actually and potentially existing, while the interpretation of a sentence is not contextually restricted to a bounded domain (Carlson 1977a, Leslie 2007; Teichman 2015). The unbounded character of generics, according to Declerck (1991: 83-84), depends on interpretative rules that ensure that the information conveyed by an utterance is maximised: maximal-set principle and inclusiveness principle. The first principle requires that the maximal set of entities is referred to, and the second one requires the application of predication on a set $\mathrm{X}$ to all members of $\mathrm{X}$.

Declerck (1991: 80) claims that a generic set is the maximal set of entities satisfying a particular description. The generic set of dogs is, therefore, the set of all entities that satisfy the description $d o g$ in any possible world. That is how maximality relates to unboundedness. The proposed maximal-set principle stipulates that "when the speaker uses a description referring to a set, the hearer has the right to assume that the intended set is the largest possible set of entities satisfying the description and the NPinherent and contextual restrictions". This principle follows from Grice's (1975: 45) Maxim of Quality, that is, if a statement is applicable only to a subset of a set, then it is misleading to use it in connection with the set as a whole. And a statement about a set as a whole will not be interpreted as only applicable to a particular subset of this set. Consider (19) and (20):

$$
\begin{aligned}
& \text { Dogs bark. }=\text { All }(\text { relevant } / \text { possible/normal) dogs bark. } \\
& \text { Dogs are barking. } \neq \text { All dogs are barking. }
\end{aligned}
$$

In (19) the reference of the NP is restricted neither by the form of the NP itself (there is no overt determiner to restrict the domain of reference), nor by the context, nor by pragmatic factors. So, the hearer will conclude that the reference here is to the largest set of entities satisfying the description of dogs, i.e. the generic set. However, in (20) the reference of the NP is restricted by the temporal anchoring (the progressive aspect and the present tense of the verb) and the description gets interpreted existentially.

It should be underlined that the maximal reading of the subject in (19) is achieved at the time of utterance (at its interpretation), therefore, it is a pragmatic effect, which is different from the maximality associated with the definite article. It is also important to notice that the maximal-set principle is applied within the boundaries of the relevantmember restriction (Declerck 1991: 83), which may explain the tolerance of exceptions for generic sentences. Thus, statements such as Whales give birth to live young, are considered acceptable, even though it is only true about female representatives of the kind whale. So, the relevant-member restriction largely depends on the pragmatic knowledge of the world that the interlocutors have. 


\subsection{Identifiability}

The perceived definite reading of generics plurals is also related to their identifiability (Lyons 1999), which means that the hearer can identify the referent used by the speaker. In order to be identified generics do not need to be 'old', that is, previously mentioned in the immediate discourse, but there has to be some kind of reference to them in the context of an utterance. Such context includes previous utterances but also the speech situation (the location, the interlocutors and their assumptions about the world, salient objects, etc.). The context is what includes a shared encyclopedic knowledge of the speakers or a shared "mental catalogue" of conceptual information, which is part of the "common ground" (Stalnaker 1978). ${ }^{22}$

Characterising sentences, in which the bare plural subject is interpreted generically, suggest that the speaker has to have some background conceptual knowledge of the subject. To put it another way, in order to characterise a kind (or a concept), one needs to have an idea of what this kind is. For instance, so as to say Dogs bark, the speaker needs to have previous knowledge of what dogs are, i.e., be familiar with the idea of $\operatorname{dog} s$ as a class of objects. Thus, familiarity, which generally characterises definite nominals can be subsumed under the notion of identifiability. The conceptual information that the speaker has about a kind includes fundamental or ontological features, but also information about the common or typical form that representatives of this kind may have, and any other relevant information (Hampton 2012). Moreover, being familiar with a certain concept and its typical/normal representatives people are quite willing to accept generic statements even when there are counterexamples and exceptions (Hampton 2012)

The interpretation of a bare plural nominal as generic or non-generic may depend on whether the hearer is familiar with the kind mentioned by the speaker and the essential properties of its representatives. Thus, (21a) may be interpreted as a characterising sentence about all relevant representatives of the kind dog, while (21b) may only be interpreted as a statement about particular (rather exceptional) cats, if the hearer is familiar with the concepts of dogs and cats:
a. Sobaki lajut.
dogs bark
'Dogs bark.'
b. Koški lajut.
cats bark
'(Some/the) cats bark. / (Some/the) cats are barking.'

\footnotetext{
22 Stalnaker (2002) defines "common ground" as presumed background information that participants in a conversation share, i.e. something that they presuppose or take for granted (see also Allan 2013). Common ground may include some items that have been explicitly introduced in the preceding discourse, physically salient objects in the local environment, but also cultural and encyclopedic knowledge (Clark \& Marshall 1981).
} 
It is also important to point out that identifiability of the referent, which belongs to the common ground, involves the idea that the existence of the referent is presupposed, which also makes generic NPs similar to definite NPs. ${ }^{23}$

\subsection{Presuppostion of existence}

Presupposition can be understood as a special condition that must be met in order for a linguistic expression to have a denotation (Frege 1892). It is usually defined as a binary relation between a pair of sentences of a language (Beaver 2001), as, for instance between (22a) and (22c). The bare plural nominal in these examples can be considered the presupposition trigger which requires the existence of multiple individuals (see Beaver \& Geurts 2011: 2433). (22a) presupposes (22c) because the truth of (22c) is a condition for the semantic value of (22a) to be true. And whenever the negation of (22a) is true (22b), (22c) is still true. Examples in (22) demonstrate the ability of presuppositions to project when embedded under negation (Beaver \& Geurts 2011, among many others):
a. Dogs bark.
b. Dogs don't bark.
c. Presupposition: Dogs exist.

In pragmatics, presupposition involves knowledge and attitudes of language users, thus, it is understood not as the presupposition of a sentence, but as a presupposition of the speaker (Stalnaker 1974, 1978, Beaver 2001). In such theories, presuppositions do not need to be associated with a certain linguistic form, and thus, can also be applied to bare nominals. Karttunen (1973: 169-170) explains the pragmatic notion of presupposition in the following way: "sentence A pragmatically presupposes B" can be understood as an abbreviation for "whenever A is uttered sincerely, the speaker of A presupposes B."

Presuppositions, according to Stalnaker (1978: 320), "are what is taken by the speaker to be the common ground of the participants in the conversation, what is treated as their common knowledge or mutual knowledge." The information that is already in the common ground and cannot be negated, as illustrated in (22).

(22) A: Pandas are on the verge of extinction.

B: $\quad$ No, this is not the case.

$\Rightarrow$ Pandas are not on the verge of extinction. They are numerous.

$\nRightarrow$ It's not pandas, it's rhinos that are on the verge of extinction.

Dealing with characterising sentences that contain bare (i.e. non overtly definite) nominals (in Russian and English), I rely on the notion of pragmatic presupposition, which is related to the knowledge and assumptions of the speaker. Generic definite

${ }^{23}$ In semantics, the existence presupposition is commonly associated with definite nominal phrases (Frege 1892, Strawson 1952). 
plurals in languages such as Romance can be said to have the semantic presupposition of existence due to the presence of the overt definite article (Robinson 2005: 99). ${ }^{24}$

The presupposition of existence of generic bare plurals can be triggered by the information structure of a sentence. Subjects of characterising sentences are interpreted as aboutness topics. As the topic is familiar to both the speaker and the addressee, the existence of the referent of the NP in topic position is not asserted or questioned by the sentence; the presupposition is taken as a common ground of the conversation. The link between topichood and the presupposition of existence is stated in many works, e.g. Gundel (1977), Reinhart (1981, 1995), Hajičová (1984).

The relevance of information structure in the interpretation of generics has been established by several authors (Reinhart 1981, Krifka et al. 1995, Cohen 2001, Krifka 2003, among others). As has been shown in a cross-linguistic study of 30 languages carried out by Gundel (1988), in some languages there is a strong tendency, in others it is obligatory for topics to be definite or generic.

Notice that in order to be topics generics do not need to be discourse-old. As Brunetti (2009) argues, for the utterance to be regarded felicitous, discourse-oldness of an aboutness topic is an adequate although not a necessary condition. Furthermore, the referent of the topical NP does not have to be known to the hearer, but it must be the case that the speaker presupposes that the addressee knows the referent. By contrast, the hearer, when an unknown entity is introduced as a topic, has at least two strategies: either to accommodate the information at stake into their knowledge without letting know that the referent is unfamiliar to them, or to interrupt the conversation to clarify the topic. In both cases the hearer updates their knowledge to repair inconsistencies between the actual common ground and the one assumed by the speaker (Mori \& Hitomi 2014).

In Russian, the information structure of a sentence may be reflected in the word order. The alternation of the basic components SV/VS brings out a contrast between the preferred generic/definite interpretation of preverbal subjects (23), and the indefinite interpretation of postverbal subjects (24).

Sobaki lajut.

generic/definite/\#indefinite

dogs bark

'Dogs bark.'/'The dogs bark./are barking.'

Lajut sobaki.

bark dogs

'Some dogs are barking.'

SV order in Russian normally represents a division into Topic and Focus, so the subject acts as given or mentioned before, and the predicate represents the new information. The preverbal argument position is strongly associated with Topic (see

\footnotetext{
24 The presuppositional character of subjects (regardless of their morphosyntactic realisation) of characterising sentences was also posited in Diesing (1992) and Kratzer (1995). They claim that subjects of $i$ level predicates are presuppositional, proposing a syntactic explanation for this phenomenon: such subjects are merged VP-externally, unlike subjects of s-level predicates. These syntactic differences are outside the scope of this paper but can be interesting for further research.
} 
Erteschik-Shir 2007 who posits that the left periphery of the sentence is generally reserved for topics). Brun (2001), Geist (2010), Jasinskaja (2014), among others, point out that in Russian utterances with a neutral intonation and without sentence stress topics appear in the leftward position, which is a preverbal position for sentences with intransitive verbs. The topic position is not particularly well-suited for new discourse referents, that is why bare nominals in Russian have a 'definite flavour'.

As for the VS order illustrated in (24), it represents a zero-Topic sentence, i.e. the one that gives entirely new information (Bailyn 2011: 261). The postverbal argument in such sentences is part of the Focus, that is why its preferred reading is indefinite to the exclusion of a generic one.

From examples (23)-(24) it can be seen that there is indeed a strong affinity between definiteness and genericity in Russian. Both generic and definite subjects are topics and they tend to occur preverbally in Russian. In general it is plausible to suggest that genericity, definiteness and topicality overlap due to their identifiability function.

\section{Discussion: Languages with articles}

In the previous section, I have shown that generics behave much like definites because they meet some of the semantic and pragmatic criteria for definite reference, which are maximality (inclusiveness) and identifiability. Moreover, they can be considered presuppositional. Nevertheless, all this does not imply that languages, even those with article systems, have to represent generics as definite in overt morphosyntax.

Lyons (1999) in his book on definiteness claims that generic plural nominals have a lot in common with definites in terms of behaviour and even proposes that they might be semantically definite expressions which do not necessarily appear in a definite form in certain languages, e.g. English. Furthermore, the author compares them to proper names, which are semantically definite, but they are not necessarily preceded by the definite article (Lyons 1999: 157). ${ }^{25}$ The ability of bare plurals in English to be interpreted as definite is also discussed in Krifka et al. (1995: 73). Previously, a similar idea about English was explicitly expressed in Carlson (1979: 65): "Bare plural NPs will be treated as definite descriptions of a very special sort". Carlson (1977a) claimed that generic bare plurals in English behave in a way which is rather similar to referring expressions than quantifiers. $^{26}$

It should also be noted that diachronically English allowed the use of definite plurals to express genericity, just as modern Romance languages do (Crisma \& Pintzuk 2016). According to Mustanoja (1960: 253), the majority of Old English uses of generic plurals occur with a definite article, however, in Middle English bare generic

${ }^{25} \mathrm{Cf}$. the use of the definite article with people's names in Catalan, Greek and some dialects of German.

${ }^{26}$ For instance, if an antecedent of a pronoun is a name or a definite expression, it can easily replace this pronoun. However, this does not happen with indefinite antecedents (Cohen 2002: 17, ex. 47a-c), as illustrated in the following examples:

(i) a. $\quad$ Fred $_{\mathrm{i}}$ walked into the room. $\{\mathrm{He}, \text { Fred }\}_{\mathrm{i}}$ smiled.

b. A man $n_{i}$ walked into the room. $\{\text { He, \#A man }\}_{\mathrm{i}}$ smiled.

c. Dogs $\mathrm{s}_{\mathrm{i}}$ are intelligent mammals. $\{\text { They, Dogs }\}_{\mathrm{i}}$ are also man's best friend. 
plurals become more widespread. Lyons (1999: 181-182) observes that plural and mass generics can be definite in the synchronic state of English too, with a limited range of nouns, nouns of nationalities and some nouns denoting classes of classes, see examples (26a)-(26c) from Lyons (1999: 181-182, ex. 63b, 64a, b).

(26) a. The dinosaurs dominated the earth for a very long time.

b. The cats - at least the big ones like tiger and pumas - are particularly fierce predators.

c. John has a soft spot for the Finns.

Carlson (2011: 1173) also points out that definite generic plurals in English are especially suitable, when it comes to referencing people, e.g. the ancient Greeks, the Russians, however, bare plurals are perfectly normal in such cases as well. That is there seem to be free variation regarding the presence or absence of the definite article.

There is also cross-linguistic evidence of variation in the use of bare vs. definite plurals with a generic meaning. For instance, in modern German, generic plurals may appear bare or with a definite article. According to Schaden (2012: 169), there seems to be free variation in cases where no categorial ambiguity is at stake (the constituent is unambiguously nominal), the predication is distributive, and the nominal constituent is topical, as illustrated in the following German examples:
a. (Die) Wale sind Säugetiere.
the-PL whales are mammals
'Whales are mammals.'
b. (Die) Dinosaurier sind ausgestorben. the-PL dinosaurs are extinct
'Dinosaurs are extinct.'

(Schaden 2012: 158, ex. 3a, b).

Another example of a language with articles, where bare nominals may have a generic interpretation, is Brazilian Portuguese (Cyrino \& Espinal 2015: 472, ex. 1b, c). (28) is an example of a generic statement, where the subject refers to a maximal plural object, independently of whether the article is present or omitted.

$$
\begin{aligned}
& \text { (Os) brasileiros são trabalhadores. } \\
& \text { the-PL.MASC Brazilians are hard-working } \\
& \text { 'Brazilians are hard-working.' }
\end{aligned}
$$

It is important to notice that this optionality of the definite article applies to plurals only with a generic reading. Bare plurals in languages such as English, German or Brazilian Portuguese, cannot be used to refer deictically or anaphorically (Dayal 2011).

In order to account for the inter- and intra-linguistic linguistic variation in the expression of genericity by means of plural nominals, I propose that, even though some languages mark definiteness on generics overtly, like most Romance languages, and others, such as English and Russian, resort to bare nominals, the interpretation of 
nominals stays the same cross-linguistically due to the universal nature of genericity in languages, related to a human cognitive ability of categorisation. This interpretation involves reference to a maximal set of individual members of a kind, which exists in the background knowledge of the participants of communication and, thus, can be identified by them. This interpretation can be encoded semantically by means of a definite article or inferred pragmatically, when a bare nominal is used.

\section{Conclusions}

In this article, I have discussed the generic reading of Russian bare plural nominals in subject position. I have argued that generic bare plurals are expressions of indirect reference to kinds, which is understood as intensionalisation of a sum of individual representatives (instantiations) of a given kind. Unlike definite kinds, which represent direct reference to kinds and are integral abstract entities, generic bare plurals are built on pluralities and, thus, give access to individual representatives of a kind. Their sum is interpreted as maximal, i.e. the reference is to all the (possible/relevant) members of a kind, which are infinitely many.

This type of reading is not the default one for bare plural nominals. I propose that the default (and the only one derived semantically) interpretation of bare nominals in Russian is indefinite and give empirical evidence for it. A generic interpretation is pragmatically inferred when a bare plural nominal is found in argument position of kindlevel predicates or functions as a subject of a characterising statement. In order for a nominal to be interpreted generically, it cannot be spatiotemporally or anaphorically anchored. Otherwise, a definite interpretation is more salient.

By and large, genericity and definiteness manifest a strong affinity: in both cases the plural nominal is interpreted as maximal, it is identifiable (at least to the speaker) and its existence is presupposed. In the case of generic nominals, it is the existence of a kind in the background knowledge of the speaker. Generic bare plurals in subject position are also interpreted as topics.

Finally, I suggest that cross-linguistically the definiteness effects of generic nominals, such as maximality, identifiability and presuppositionality, may be encoded semantically by a definite article or inferred pragmatically on bare nominals. This may also account for the free variation in the use of definite vs. bare plural NPs for the expression of genericity in some languages.

\section{References}

Allan, K. 2013. What is common ground? In A. Capone, F. Lo Piparo \& M. Carapezza (eds.), Perspectives in Pragmatics, Philosophy and Psychology, 285-310. Cham: Springer.

Bailyn, J. F. 2011. The Syntax of Russian. Cambridge: Cambridge University Press.

Beaver, D. 2001. Presupposition and Assertion in Dynamic Semantics. Stanford, CA: CSLI Publications.

Beaver, D. \& Geurts, B. 2011. Presupposition. In K. von Heusinger, C. Maienborn \& P. Portner (eds.), Semantics, vol. 2, 2432-2460. Berlin: De Gruyter Mouton.

Behrens, L. 2005. Genericity from a cross-linguistic perspective. Linguistics 43 (2): 275-344. 
Beyssade, C. 2005. Les définis génériques en français: noms d'espèces ou sommes maximales. In C. Dobrovie-Sorin (ed.), Noms nus et généricité, 33-63. Paris: Presse de Vincennes.

Borik, O. \& Espinal, M. T. 2015. Reference to kinds and to other generic expressions in Spanish: Definiteness and number. The Linguistic Review 32 (2): 167-225.

Borik, O. \& Espinal, M. T. 2019a. Definiteness in Russian bare nominal kinds. In. J. Pozas Loyo, A. AguilarGuevara \& V. Vázquez-Rojas Maldonado (eds.), Definiteness across languages, 293-318. Berlin: Language Science Press.

Borik, O. \& Espinal, M. T. 2019b. Numberless kinds: Evidence from Russian. Ms. UNED/UAB.

Bronnikov, G. 2006. A critique of Dayal (2004). Ms. https: //www.academia.edu/6055945/A_critique_of_ Dayal_2004.

Bronnikov, G. 2007. Bare NPs in Russian. AATSEEL handout.

Brun, D. 2001. Information structure and the status of NP in Russian. Theoretical Linguistics 27 (2-3): 10-26. Brunetti, L. 2009. On links and tails in Italian. Lingua 119 (5): 756-781.

Carlson, G. N. 1977a. A unified analysis of the English bare plural. Linguistics and Philosophy 1 (3): 413-457.

Carlson, G. N. 1977b. Reference to kinds in English. PhD dissertation, University of Massachusetts.

Carlson, G. N. 1979. Generics and atemporal 'when'. Linguistics and Philosophy 3 (1): 49-98.

Carlson, G. N. 2011. Genericity. In K. von Heusinger, C. Maienborn \& P. Portner (eds.), Semantics, vol. 2, 1153-1185. Berlin: De Gryuter Mouton.

Chierchia G. 1984. Topics in the Syntax and Semantics of Infinitives and Gerunds. PhD dissertation. Amherst: University of Massachusetts.

Chierchia, G. 1998. Reference to kinds across languages. Natural Language Semantics 6 (4): 339-405.

Clark, H. 1975. Bridging. In R. Schank \& B. Nash-Webber (eds.), Theoretical issues in natural language Processing 169-174. Cambridge, MA: MIT.

Clark, H. \& C. Marshall. 1981. Definite knowledge and mutual knowledge. In A. K. Joshi, B. L. Webber \& I. A. Sag. (eds.), Elements of Discourse Understanding, 10-63. Cambridge: Cambridge University Press.

Cohen, A. 2001. On the Generic Use of Indefinite Singulars. Journal of Semantics 18 (3): 183-209.

Cohen, A. 2002. Genericity. Linguistische Berichte 10: 59-89.

Crisma, P. \& S. Pintzuk. 2016. An from Old to Middle English. In S. Vikner, H. Jørgensen \& E. van Gelderen (eds.), Let us Have Articles betwixt us, 31-53. Aarhus: Department of English, School of Communication and Culture, Aarhus University.

Cyrino, S. \& Espinal, M. T. 2015. Bare nominals in Brazilian Portuguese: More on the DP/NP analysis. Natural Language and Linguistic Theory 33 (2): 471-521.

Dahl, Ö. 1975. On generics. In E. L. Keenan (ed.), Formal Semantics of Natural Language, 99-111. Cambridge: Cambridge University Press.

Dayal, V. 2004. Number marking and (In)definiteness in kind terms. Linguistics and Philosophy 27 (4): 393-450.

Dayal, V. 2011. Bare noun phrases. In K. von Heusinger, C. Maienborn \& P. Portner (eds.), Semantics, vol. 2, 1088-1109. Berlin: De Gryuter Mouton.

Dayal, V. 2017. Determining (In)definiteness in the absence of articles. In V. Hohaus \& W. Rothe (eds.), Proceedings of TripleA 3: Fieldwork Perspectives on the Semantics of African, Asian and Austronesian Languages, 85-99. Tübingen: Universitätsbibliothek Tübingen, Publikationssystem. https://publikationen.uni-tuebingen. de/xmlui/handle/10900/73437.

Declerck, R. 1986. The manifold interpretations of generic sentences. Lingua 68 (2-3): 149-188.

Declerck, R. 1987. A puzzle about generics. Folia Linguistica 21 (2-4): 143-154.

Declerck, R. 1991. The origins of genericity. Linguistics 29 (1): 79-102.

Déprez, V. 2005. Morphological number, semantic number and bare nouns. Lingua 115 (6): 857-883.

Diesing, M. 1992. Indefinites. Cambridge, MA: MIT Press.

Dobrovie-Sorin, C. \& Pires de Oliveira, R. 2008. Reference to kinds in Brazilian Portuguese: Definite singulars vs. bare singulars. In A. Grønn (ed.), Proceedings of SuB12, 107-121. Oslo: ILOS.

Erteschik-Shir, N. 2007. Information Structure: The Syntax-Discourse Interface. Oxford: Oxford University Press.

Espinal, M. T. 2010. Bare nominals in Catalan and Spanish. Their structure and meaning. Lingua 120 (4): 984-1009.

Espinal, M. T. \& L. McNally. 2007. Bare singular nominals and incorporating verbs. Proceedings of the III NEREUS International Workshop. Definiteness, Specificity and Animacy in Ibero-Romance languages 122: 45-62.

Farkas, D. F. \& de Swart, H. 2007. Article choice in plural generics. Lingua 117 (9): 1657-1676. 
Filip, H. 1993. On genericity: A case study in Czech. Annual Meeting of the Berkeley Linguistics Society 19 (1): $125-142$.

Filip, H. \& Carlson, G. N. 1999. Sui generis genericity. Penn Working Papers in Linguistics 4: 91-110.

Frege, G. 1892. Über Sinn und Bedeutung. Zeitschrift für Philosophie und philosophische Kritik 100: 25-50.

Geist, L. 2010. Bare singular NPs in argument positions: Restrictions on indefiniteness. International Review of Pragmatics 2 (2): 191-227.

Grice, H. P. 1975. Logic and conversation. In M. Ezcurdia \& R. J. Stainton (eds.), The Semantics-Pragmatics Boundary in Philosophy, 41-58. Peterborough: Broadview Press.

Gundel, J. K. 1977. Role of Topic and Comment in Linguistic Theory. PhD dissertation, University of Texas, Austin. Reproduced by Indiana University Linguistics Club.

Gundel, J. K. 1988. Universals of topic-comment structure. In M. Hammond (ed.), Studies in Syntactic Typology, 209-242. Amsterdam/Philadelphia: John Benjamins Publishing Company.

Hajičová, E. 1984. On presupposition and allegation. In P. Sgall (ed.), Contributions to Functional Syntax, Semantics and Language Comprehension, 99-122. Amsterdam/Philadelphia: John Benjamins.

Hampton, J. A. 2012. Generics as reflecting conceptual knowledge. Recherches linguistiques de Vincennes 41: 9-24.

Hawkins, J. 1978. Definiteness and Indefiniteness: A Study in Reference and Grammaticality Prediction. London: Croom Helm.

Heim, I. 2011. Definiteness and indefiniteness. In K. von Heusinger, C. Maienborn \& P. Portner (eds.), Semantics, vol. 2, 1025-1058. Berlin: De Gruyter Mouton.

Jasinskaja, K. 2014. Information structure in Slavic. In C. Féry \& S. Ishihara (eds.), Handbook of Information Structure, 709-732. Oxford: Oxford University Press.

Jespersen, O. 1927. A Modern English Grammar on Historical Principles. London: Allen and Unwin.

Karttunen, L. 1973. Presuppositions of Compound Sentences. Linguistic Inquiry 4 (2): 169-193.

Kratzer, A. 1995. Stage-level and individual-level predicates. In G. N. Carlson \& F. J. Pelletier (eds.), The Generic Book, 125-175. Chicago: University of Chicago Press.

Krifka, M. 2003. Bare NPs: Kind-referring, indefinites, both, or neither? Semantics and Linguistic Theory 13: 180-203.

Krifka, M. \& Gerstner, C. 1987. An Outline in Genericity. SNS-Bericht. Seminar für natürlich-sprachliche Systeme der Universität Tübingen.

Krifka, M., Pelletier, F. J, Carlson, G. N., Ter Meulen, A., Link, G. \& Chierchia, G. 1995. Genericity: An introduction. In G. N. Carlson \& F. J. Pelletier (eds.), The Generic Book, 1-124. Chicago: University of Chicago Press.

Kuroda, Y.-S. 1972. The categorical and the thetic judgment: Evidence from Japanese syntax. Foundations of Language 9: 153-185.

Laca, B. 1990. Generic objects: Some more pieces of the puzzle. Lingua 81 (1): 25-46.

Lawler, J. M. 1973. Studies in English Generics. PhD dissertation University of Michigan Ann Arbor.

Leslie, S.-J. 2007. Generics and the structure of the mind. Philosophical Perspectives 21 (1): 375-403.

Longobardi, G. 2001. How comparative is semantics? A unified parametric Theory of bare nouns and proper names. Natural Language Semantics 9 (4): 335-369.

Lyons, C. 1999. Definiteness. Cambridge: Cambridge University Press.

Mari, A., Beyssade, C. \& Del Prete, F. 2012. Introduction. In A. Mari, C. Beyssade \& F. Del Prete (eds.), Genericity, 1-92. Oxford: Oxford University Press.

Montague, R. 1970. English as a Formal Language. In B. Visentini (ed.), Linguaggi nella societa e nella tecnica, 188-221. Milan: Edizioni di Communità.

Mori, Y. \& H. Hitomi. 2014. Bare plurals in the Left Periphery in German and Italian. In Y. Nakano, K. Satoh \& D. Bekki (eds.), New Frontiers in Artificial Intelligence, 82-97. Berlin: Springer International Publishing.

Mueller-Reichau, O. 2011. Sorting the World. Berlin: De Gruyter.

Mustanoja, T. F. 1960. A Middle English Syntax: Parts of Speech. Helsinki: Société néophilologique.

Müller, A. 2002. The semantics of generic quantification in Brazilian Portuguese. Probus 14 (2): 279-298.

Partee, B. H. 1987. Noun phrase interpretation and type-shifting principles. In J. Groenendijk \& M. Stokhof (eds.), Studies in Discourse Representation Theory and the Theory of Generalized Quantifiers, 115143. Dordrecht: Foris. 
Prasada, S. 2016. Mechanisms for thinking about kinds, instances of kinds, and kinds of kinds. In D. Barner \& A. S. Baron (eds.), Core Knowledge and Conceptual Change, 209-224. Oxford: Oxford University Press.

Reinhart, T. 1981. Pragmatics and linguistics: An analysis of sentence topics. Philosophica 27 (1): 53-94.

Reinhart, T. 1995. Interface strategies. OTS Working Papers in Linguistics.

Reinhart, T. 1997. Quantifier scope: How labor is divided between QR and choice functions. Linguistics and Philosophy 20 (4): 335-397.

Robinson, H. 2005. Unexpected (In)definiteness: Plural Generic Expressions in Romance. PhD dissertation, Rutgers University.

Schaden, G. 2012. Two ways of referring to generalities in German. In A. Mari, C. Beyssade \& F. Del Prete (eds.), Genericity, 157-175. Oxford: Oxford University Press.

Schwarz, F. 2012. Different types of definites crosslinguistically. Ms. https://semanticsarchive. net/Archive/ jRlOGQwN/CrossLingDef.pdf.

Seres, D. 2020. The Expression of Genericity in Languages with and without Articles. PhD dissertation, Universitat Autònoma de Barcelona.

Seres, D. \& Borik, O. in press. Definiteness in the absence of uniqueness: The case of Russian. Advances in Formal Slavic Linguistics 2018. Berlin: Language Science Press.

Seres, D. \& Espinal, M. T. 2018. Psychological verbs and their arguments. Borealis - An International Journal of Hispanic Linguistics 7 (1): 27- 44.

Seres, D. \& Espinal, M. T. 2019. Internal arguments of psychological verbs and their interpretations. In N. Pomino (ed.), Proceedings of the IX Nereus International Workshop "Morphosyntactic and semantic aspects of the DP in Romance and beyond". Arbeitspapier 131. Arbeitspapiere / Fachbereich Linguistik (bis 2018 Fachbereich Sprachwissenschaft), 91-107. Konstanz: Fachbereich Linguistik der Universität Konstanz.

Sharvy, R. 1980. A more general theory of definite descriptions. The Philosophical Review 89 (4): 607-624.

Stalnaker, R. 1974. Pragmatic presuppositions. In R. Stalnaker (ed.), Context and Content, 47-62. Oxford: Oxford University Press.

Stalnaker, R. 1978. Assertion. Syntax and Semantics 9: 315-332.

Stalnaker, R. 2002. Common ground. Linguistics and Philosophy 25 (5/6): 701-721.

Strawson, P. F. 1952. Introduction to Logical Theory. London: Methuen.

Teichman, M. 2015. Characterizing Kinds: A Semantics for Generic Sentences. PhD dissertation, University of Chicago.

Topolinjska, Z. 2006. Toward a definition of the generic noun phrase. Linguistica 46 (1): 55-59.

Vendler, Z. 1967. Linguistics in Philosophy. Ithaca: Cornell University Press. 